\title{
Prenylated Indolediketopiperazine Peroxides and Related Homologues from the Marine Sediment-Derived Fungus Penicillium brefeldianum SD-273
}

\section{Chun-Yan An ${ }^{1,2}$, Xiao-Ming $\mathrm{Li}^{1}$, Chun-Shun $\mathrm{Li}^{1}$, Gang-Ming $\mathrm{Xu}^{1}$ and Bin-Gui Wang ${ }^{1, *}$}

1 Key Laboratory of Experimental Marine Biology, Institute of Oceanology, Chinese Academy of Sciences, Nanhai Road 7, Qingdao 266071, China; E-Mails: anchy5885@gmail.com (C.-Y.A.); lixmqd@yahoo.com.cn (X.-M.L.); lichunshun@ms.qdio.ac.cn (C.-S.L.); aericxu@gmail.com (G.-M.X.)

2 University of Chinese Academy of Sciences, Yuquan Road 19A, Beijing 100049, China

* Author to whom correspondence should be addressed; E-Mail: wangbg@ms.qdio.ac.cn; Tel./Fax: +86-532-8289-8553.

Received: 21 November 2013; in revised form: 10 January 2014 / Accepted: 15 January 2014 / Published: 27 January 2014

\begin{abstract}
Three new indolediketopiperazine peroxides, namely, 24-hydroxyverruculogen (1), 26-hydroxyverruculogen (2), and 13-O-prenyl-26-hydroxyverruculogen (3), along with four known homologues (4-7), were isolated and identified from the culture extract of the marine sediment-derived fungus Penicillium brefeldianum SD-273. Their structures were determined based on the extensive spectroscopic analysis and compound $\mathbf{1}$ was confirmed by X-ray crystallographic analysis. The absolute configuration of compounds 1-3 was determined using chiral HPLC analysis of their acidic hydrolysates. Each of the isolated compounds was evaluated for antibacterial and cytotoxic activity as well as brine shrimp (Artemia salina) lethality.
\end{abstract}

Keywords: marine sediment; Penicillium brefeldianum SD-273; indolediketopiperazine; brine shrimp lethality

\section{Introduction}

Indolediketopiperazine alkaloids are a series of natural occurring secondary metabolites generally formed from L-tryptophan and other common amino acids, e.g., L-proline, L-alanine, and D-valine [1-8]. 
Some of these compounds showed tremor-producing, cytotoxic, antibacterial, and brine shrimp lethal activity [3-7]. In our continuing investigation aimed to explore new and bioactive secondary metabolites from marine-derived fungi [9-15], we recently focused on a fungal strain Penicillium brefeldianum SD-273 that was isolated from the sediment samples collected from the estuary of the Pearl River in the South China Sea. The EtOAc extract of the fermentation broth showed moderate brine shrimp (Artemia salina) lethality in the preliminary assays. Further investigation of the culture extracts of this fungus resulted in the isolation of three new indolediketopiperazine peroxides (1-3) and four known homologues (4-7) (Figure 1). The structure of these compounds was determined by spectroscopic analysis and compound $\mathbf{1}$ was confirmed by X-ray crystallographic experiment. The absolute configuration of compounds 1-3 was determined by chiral HPLC analysis of their acidic hydrolysates. It should be noted that, based on our 1D and 2D NMR data, the original assignment of the carbon signals for the two methyls in the isoprenyl moiety of verruculogen (4) [4] should be interchanged. This paper describes the isolation, structure determination, and bioactivity evaluation of the isolated compounds.

Figure 1. The structures of isolated compounds 1-7.
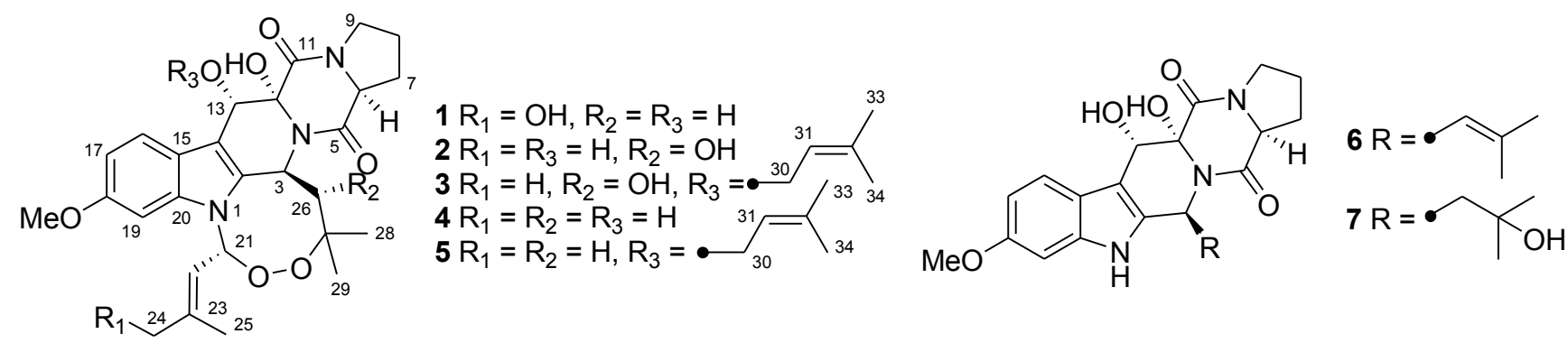

\section{Results and Discussion}

\subsection{Structure Elucidation of the New Compounds 1-3}

The cultured broth and mycelia of the fungus were exhaustively extracted with EtOAc and $\mathrm{MeOH}$, respectively. Since the HPLC and TLC profiles of the two extracts were nearly identical, they were combined before further separation. The combined extract was fractionated by a combination of column chromatography (CC) on Si gel, reversed-phase Si gel C18, and Sephadex LH-20 as well as by semi-preparative HPLC and preparative thin layer chromatography (pTLC), to yield seven indolediketopiperazine derivatives (1-7) (Figure 1).

Compound 1 was obtained as colorless crystals. The HRESIMS experiment established its molecular formula $\mathrm{C}_{27} \mathrm{H}_{33} \mathrm{~N}_{3} \mathrm{O}_{8}$. Inspection of the ${ }^{1} \mathrm{H}-,{ }^{13} \mathrm{C}$-, and DEPT NMR data of 1 revealed the presence of four methyls (with one $O$-methyl group), five $\mathrm{sp}^{3}$ methylenes (with one oxygenated), four $\mathrm{sp}^{3}$ and four $\mathrm{sp}^{2}$ methines, and ten quaternary carbons (with two oxygenated $\mathrm{sp}^{3}$ and $\mathrm{six} \mathrm{sp}^{2}$ carbons and two ester/amide carbons), as well as three exchangeable protons (Table 1). The ${ }^{1} \mathrm{H}-$ and ${ }^{13} \mathrm{C}-\mathrm{NMR}$ data assignments matched well with those of the corresponding signals for verruculogen (4), a tremorgenic mycotoxin peroxide isolated from peanuts-derived fungus Penicillium verruculosum [4,5], except for the presence of the C-24 hydroxy group, which was consistent with the difference in the molecular formula. This difference was supported by the fact that the NMR signals for one of the two 
methyls in the prenyl moiety of $4[4,5]$ were replaced by the downfield oxygenated $\mathrm{CH}_{2}$ signals at $\delta_{\mathrm{H}} 3.80 / \delta_{\mathrm{C}} 65.2\left(\mathrm{CH}_{2}-24\right)$ in the NMR spectra of 1 (Table 1$)$. The HMBC correlations from H-22 to C-24 and C-25, from $\mathrm{H}_{2}-24$ to $\mathrm{C}-22$ and $\mathrm{C}-23$, and from $\mathrm{H}_{3}-25$ to $\mathrm{C}-22, \mathrm{C}-23$, and $\mathrm{C}-24$ verified the above deduction (Figure 2). The observed NOE correlations from H-26 $\alpha$ to H-3 and H-6 and from H-3 to H-22 indicated that these protons located on the same face of the molecule (Figure 3). In addition, NOE correlation from $\mathrm{H}-22$ to the proton of $24-\mathrm{OH}$ established the $E$-geometry for the double bond at C-22. However, the relative configuration for $12-\mathrm{OH}$ and $13-\mathrm{OH}$ was not assigned since no diagnostic NOE correlations could be detected.

Table 1. ${ }^{1} \mathrm{H}$ and ${ }^{13} \mathrm{C}$ NMR data of compounds $1-3^{\text {a }}$.

\begin{tabular}{|c|c|c|c|c|c|c|}
\hline \multirow{2}{*}{ No. } & \multicolumn{2}{|l|}{1} & \multicolumn{2}{|l|}{2} & \multicolumn{2}{|l|}{3} \\
\hline & $\delta_{H}(J$ in Hz $)$ & $\boldsymbol{\delta}_{\mathrm{C}}$ & $\delta_{\mathrm{H}}(J$ in $\mathrm{Hz})$ & $\boldsymbol{\delta}_{\mathrm{C}}$ & $\delta_{H}(J$ in $H z)$ & $\boldsymbol{\delta}_{\mathrm{C}}$ \\
\hline 2 & & $131.4, \mathrm{C}$ & & $129.6, \mathrm{C}$ & & $129.8, \mathrm{C}$ \\
\hline 3 & $5.89, \mathrm{~d}(10.0)$ & $48.3, \mathrm{CH}$ & $6.13, \mathrm{~d}(8.8)$ & $49.1, \mathrm{CH}$ & $6.20, \mathrm{~d}(9.0)$ & $48.4, \mathrm{CH}$ \\
\hline 5 & & 171.1, C & & $170.7, \mathrm{C}$ & & $171.4, \mathrm{C}$ \\
\hline 6 & $4.45, \mathrm{t}(8.0)$ & $58.8, \mathrm{CH}$ & $4.35, \mathrm{t}(7.9)$ & $58.7, \mathrm{CH}$ & $4.45, \mathrm{t}(8.2)$ & $58.9, \mathrm{CH}$ \\
\hline 7 & $\begin{array}{l}\alpha 2.30, \mathrm{~m} \\
\beta 1.88, \mathrm{~m}\end{array}$ & 29.3, $\mathrm{CH}_{2}$ & $\begin{array}{l}\alpha 2.33, \mathrm{~m} \\
\beta 1.90, \mathrm{~m}\end{array}$ & $29.5, \mathrm{CH}_{2}$ & $\begin{array}{l}\alpha 2.30, \mathrm{~m} \\
\beta 1.87, \mathrm{~m}\end{array}$ & $29.2, \mathrm{CH}_{2}$ \\
\hline 8 & $1.94, \mathrm{~m}$ & 22.6, $\mathrm{CH}_{2}$ & $1.90, \mathrm{~m}$ & $22.1, \mathrm{CH}_{2}$ & $1.87, \mathrm{~m}$ & $22.5, \mathrm{CH}_{2}$ \\
\hline 9 & $\begin{array}{c}\alpha 3.44, \mathrm{~m} \\
\beta 3.50, \mathrm{t}, 8.2\end{array}$ & $45.5, \mathrm{CH}_{2}$ & $\begin{array}{l}\alpha 3.44, \mathrm{~m} \\
\beta 3.52, \mathrm{~m}\end{array}$ & $44.8, \mathrm{CH}_{2}$ & $\begin{array}{l}\alpha 3.40, \mathrm{~m} \\
\beta 3.52, \mathrm{~m}\end{array}$ & $45.2, \mathrm{CH}_{2}$ \\
\hline 11 & & $166.5, \mathrm{C}$ & & 166.0, C & & $165.5, \mathrm{C}$ \\
\hline 12 & & $82.1, \mathrm{C}$ & & $82.6, \mathrm{C}$ & & $84.1, \mathrm{C}$ \\
\hline 13 & $5.40, \mathrm{~s}$ & $68.4, \mathrm{CH}$ & $5.43, \mathrm{~s}$ & $68.1, \mathrm{CH}$ & $5.12, \mathrm{~s}$ & $73.5, \mathrm{CH}$ \\
\hline 14 & & 107.9, C & & 107.8, C & & $107.5, \mathrm{C}$ \\
\hline 15 & & $121.3, \mathrm{C}$ & & $120.6, \mathrm{C}$ & & $120.4, \mathrm{C}$ \\
\hline 16 & $7.72, \mathrm{~d}(8.7)$ & $121.8, \mathrm{CH}$ & $7.72, \mathrm{~d}(9.3)$ & 121.1, CH & $7.57, \mathrm{~d}(8.7)$ & $120.3, \mathrm{CH}$ \\
\hline 17 & $6.69, \mathrm{dd}(8.7,1.3)$ & 109.3, CH & $6.69, \mathrm{dd}(9.3,2.1)$ & $108.7, \mathrm{CH}$ & $6.74, \mathrm{dd}(8.7,2.2)$ & $108.8, \mathrm{CH}$ \\
\hline 18 & & $156.0, \mathrm{C}$ & & $155.3, \mathrm{C}$ & & $155.3, \mathrm{C}$ \\
\hline 19 & $6.75, \mathrm{~d}(1.3)$ & $94.3, \mathrm{CH}$ & $6.70, \mathrm{~d}(2.1)$ & $93.4, \mathrm{CH}$ & $6.69, \mathrm{~d}(2.2)$ & 93.6, $\mathrm{CH}$ \\
\hline 20 & & $136.3, \mathrm{C}$ & & $135.3, \mathrm{C}$ & & $135.3, \mathrm{C}$ \\
\hline 21 & $6.88, \mathrm{~d}(8.4)$ & $85.5, \mathrm{CH}$ & $6.78, \mathrm{~d}(8.2)$ & $85.0, \mathrm{CH}$ & $6.77, \mathrm{~d}(8.2)$ & $85.1, \mathrm{CH}$ \\
\hline 22 & $5.26, \mathrm{~d}(8.4)$ & $116.0, \mathrm{CH}$ & $5.06, \mathrm{~d}(8.2)$ & $118.3, \mathrm{CH}$ & $5.02, \mathrm{~d}(8.2)$ & $118.1, \mathrm{CH}$ \\
\hline 23 & & $146.9, \mathrm{C}$ & & $142.8, \mathrm{C}$ & & 143.0, C \\
\hline 24 & $3.80, \mathrm{~s}$ & $65.2 \mathrm{CH}_{2}$ & $1.73, \mathrm{~s}$ & $25.2, \mathrm{CH}_{3}$ & $1.74, \mathrm{~s}$ & $25.4, \mathrm{CH}_{3}$ \\
\hline 25 & $1.87, \mathrm{~s}$ & $14.5, \mathrm{CH}_{3}$ & $2.00, \mathrm{~s}$ & $18.3, \mathrm{CH}_{3}$ & $2.00, \mathrm{~s}$ & $18.4, \mathrm{CH}_{3}$ \\
\hline 26 & $\begin{array}{l}\alpha 1.91, \mathrm{~m} \\
\beta 1.55, \mathrm{~m}\end{array}$ & 51.3, $\mathrm{CH}_{2}$ & $2.92, \mathrm{~d}(8.8)$ & $80.0, \mathrm{CH}$ & $2.92, \mathrm{~d}(9.0)$ & $79.3, \mathrm{CH}$ \\
\hline 27 & & $83.2, \mathrm{C}$ & & $85.0, \mathrm{C}$ & & $85.2, \mathrm{C}$ \\
\hline 28 & $1.57, \mathrm{~s}$ & 24.6, $\mathrm{CH}_{3}$ & $1.44, \mathrm{~s}$ & $18.4, \mathrm{CH}_{3}$ & $1.41, \mathrm{~s}$ & $18.3, \mathrm{CH}_{3}$ \\
\hline 29 & $0.95, \mathrm{~s}$ & $27.2, \mathrm{CH}_{3}$ & $0.99, \mathrm{~s}$ & $25.3, \mathrm{CH}_{3}$ & $0.98, \mathrm{~s}$ & $25.2, \mathrm{CH}_{3}$ \\
\hline 30 & & & & & $\begin{array}{l}4.56, \mathrm{dd}(7.0,11.0) \\
4.88, \mathrm{dd}(6.5,11.0)\end{array}$ & $68.5, \mathrm{CH}_{2}$ \\
\hline 31 & & & & & $5.57, \mathrm{t}(6.5)$ & $122.2, \mathrm{CH}$ \\
\hline
\end{tabular}


Table 1. Cont.

\begin{tabular}{|c|c|c|c|c|c|c|}
\hline 32 & & & & & & $134.5, \mathrm{C}$ \\
\hline 33 & & & & & $1.75, \mathrm{~s}$ & $18.1, \mathrm{CH}_{3}$ \\
\hline 34 & & & & & $1.77, \mathrm{~s}$ & $25.2, \mathrm{CH}_{3}$ \\
\hline $18-\mathrm{OCH}_{3}$ & $3.75, \mathrm{~s}$ & $55.8, \mathrm{CH}_{3}$ & $3.76, \mathrm{~s}$ & $55.2, \mathrm{CH}_{3}$ & $3.76, \mathrm{~s}$ & $55.2, \mathrm{CH}_{3}$ \\
\hline 12-OH & 5.10, br s $^{\mathrm{b}}$ & & 5.26, br s $^{\mathrm{b}}$ & & 6.16 , br s & \\
\hline $13-\mathrm{OH}$ & 6.68, br s $^{b}$ & & 6.32, br s ${ }^{b}$ & & & \\
\hline $24-\mathrm{OH}$ & 3.34, br s & & & & & \\
\hline $26-\mathrm{OH}$ & & & 5.52 , br s & & 5.37 , br s & \\
\hline
\end{tabular}

${ }^{a}$ Measured in DMSO- $d_{6}$, at $500 \mathrm{MHz}$ for ${ }^{1} \mathrm{H}$ and $125 \mathrm{MHz}$ for ${ }^{13} \mathrm{C}$ with reference to the solvent signals, $\delta$ in ppm;

${ }^{\mathrm{b}}$ Exchangeable signals in the same column.

Figure 2. Key HMBC (red arrows) and ${ }^{1} \mathrm{H}-{ }^{1} \mathrm{H}$ COSY (bold line) correlations of $\mathbf{1}-\mathbf{3}$.
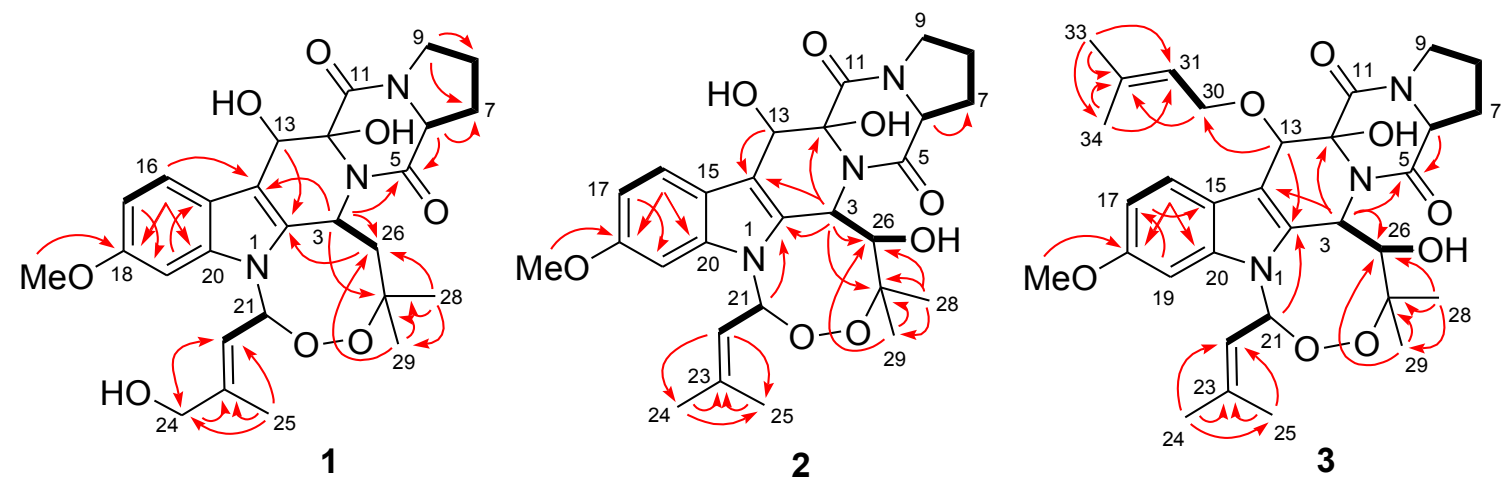

Figure 3. Key NOE correlations (double arrows) of 1-3.
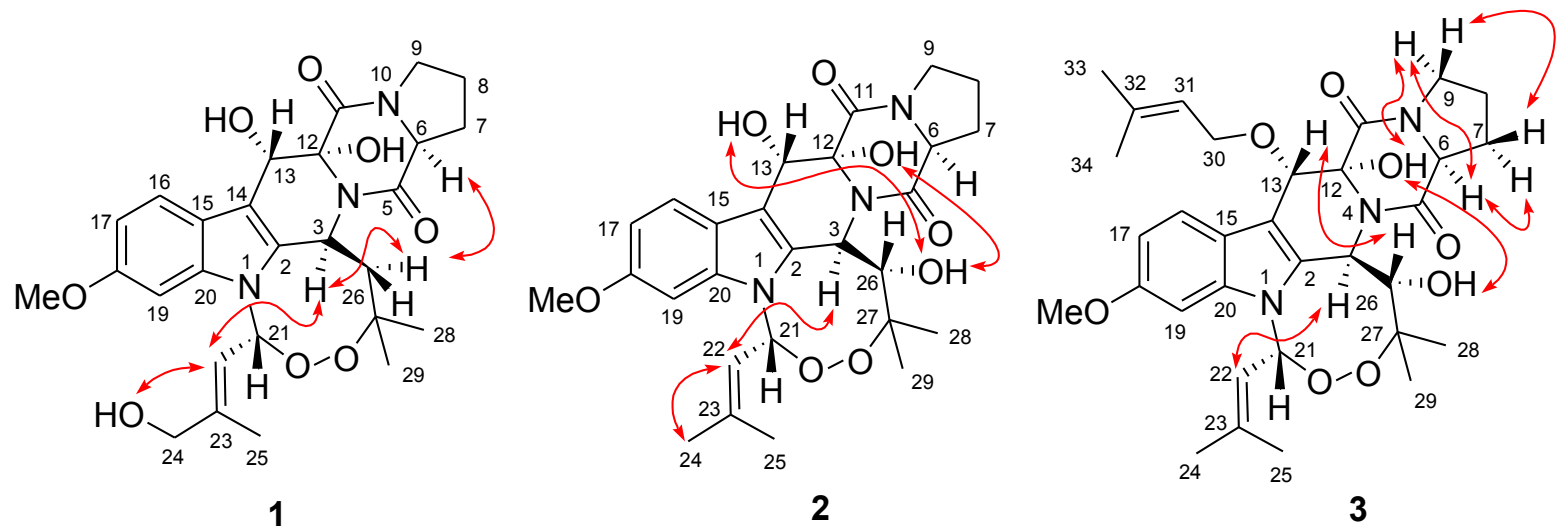

To unambiguously assign the structure, a single X-ray diffraction study was performed. However, compound 1 was difficult to get suitable crystal for X-ray analysis and after many attempts, X-ray quality crystals were obtained by slow evaporation of a solution of 1 in $\mathrm{CHCl}_{3}-\mathrm{MeOH}$ (1:1). The X-ray diffraction crystallographic analysis confirmed the structure and relative configuration for 1 (Figure 4).

The absolute configuration of $\mathbf{1}$ was deduced after chiral HPLC analysis of the degradation products of the acidic hydrolysate. The HPLC profile of the hydrolysate was compared with authentic standard to establish the configuration of the amino acid-derived unit as L-proline (Figure 5), corresponding to the $S$-configuration for C-6. The absolute configuration of compound 1 was therefore assigned to be 
$3 S, 12 R, 13 S$, and $21 R$. The structure for compound 1 was finally determined and it was named as 24-hydroxyverruculogen.

Figure 4. X-ray structure of compound 1. (Note: A different numbering system is used for the structure in the text.)

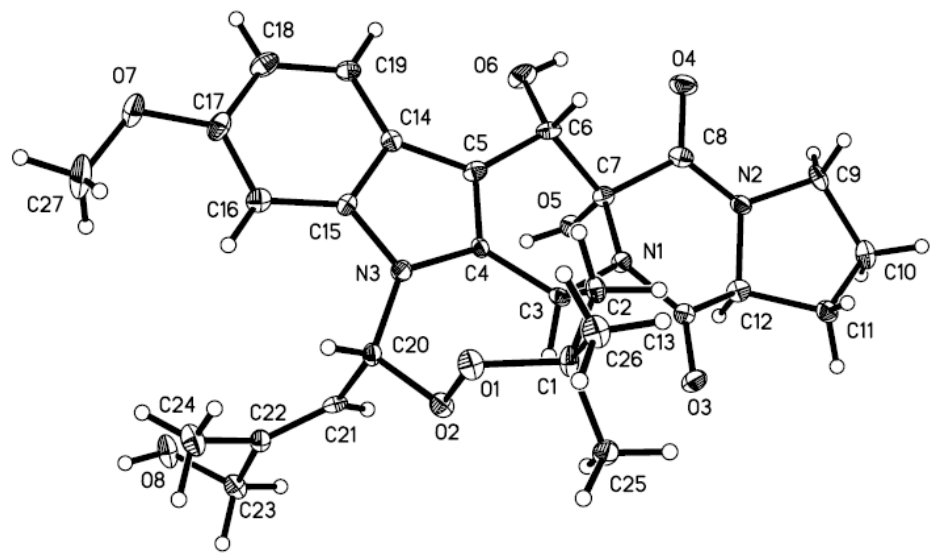

Figure 5. Chiral HPLC analysis of the amino acid derivatives of compounds 1-3 (Phenomenex-Chirex 3126 column, $250 \times 4.60 \mathrm{~mm}, 5 \mu \mathrm{m}$; Gradient: 10\% aqueous acetonitrile with $2 \mathrm{mM} \mathrm{CuSO}_{4} \cdot 5 \mathrm{H}_{2} \mathrm{O}$, detected at $225 \mathrm{~nm}$ ).

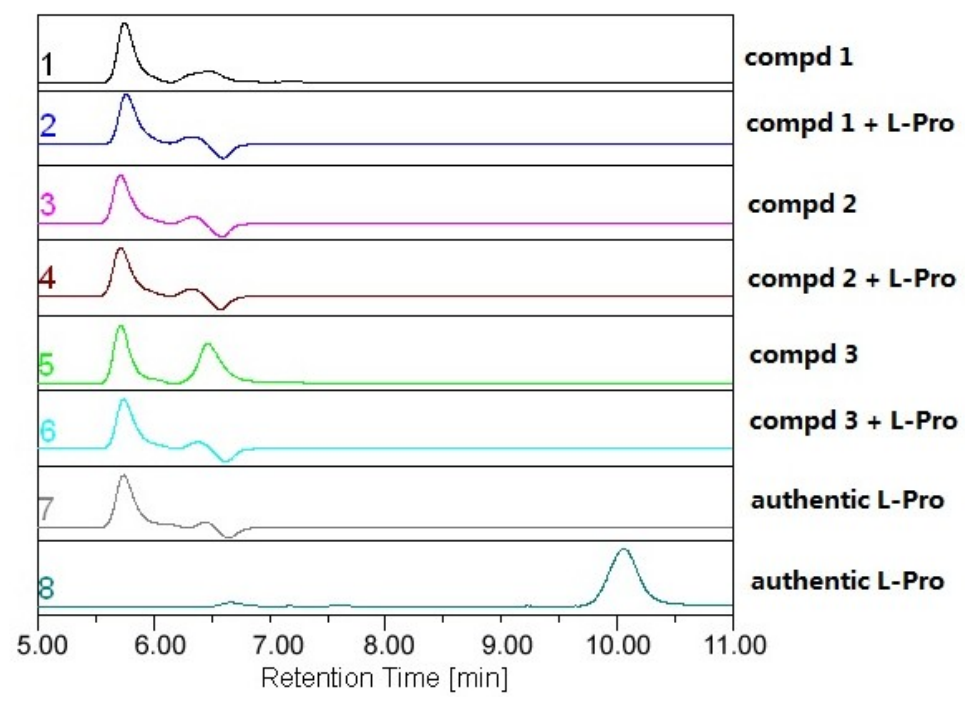

Compound 2 was isolated as a pale amorphous solid. Its molecular formula was demonstrated as $\mathrm{C}_{27} \mathrm{H}_{33} \mathrm{~N}_{3} \mathrm{O}_{8}$ by HRESIMS data. Analysis of its ${ }^{1} \mathrm{H}$ and ${ }^{13} \mathrm{C}$ NMR spectral data (Table 1) with those of verruculogen (4) indicated that both compounds shared the same indolediketopiperazine skeleton [4,5]. The main difference between the two compounds was the methylene carbon resonating at $\delta_{\mathrm{C}} 45.3$ (C-26, this carbon was numbered as C-19 in the reference 4) in the ${ }^{13} \mathrm{C}$ NMR spectrum of 4 [4] being replaced by an oxygenated methine $\left(\delta_{\mathrm{C}} 80.0, \mathrm{C}-26\right)$ in that of 2 . This difference was verified by the ${ }^{1} \mathrm{H}-{ }^{1} \mathrm{H}$ COSY correlations from oxymethine proton $\mathrm{H}-26$ to $\mathrm{H}-3\left(\delta_{\mathrm{H}} 6.13, \mathrm{~d}, J=8.8 \mathrm{~Hz}\right)$ and to the exchangeable proton signal at $\delta_{\mathrm{H}} 5.52$ (br s, 26-OH). The observed HMBC correlations from H-3, $\mathrm{H}_{3}-28$, and $\mathrm{H}_{3}-29$ to $\mathrm{C}-26$ (Figure 2) supported this deduction. Other ${ }^{1} \mathrm{H}-{ }^{1} \mathrm{H}$ COSY and $\mathrm{HMBC}$ correlations confirmed the structure of $\mathbf{2}$ (Figure 2). However, the remaining two exchangeable protons 
resonating at $\delta_{\mathrm{H}} 5.26$ and 6.32 , which belonging to $12-\mathrm{OH}$ and $13-\mathrm{OH}$, could not be unambiguously ascribed since they didn't show any correlations in the 2D NMR spectra.

The relative configuration of compound $\mathbf{2}$ was determined by NOESY experiment, proton coupling constant, and NMR data comparison. The trans-relationship between H-3 and H-26 was deduced on the basis of large coupling constant $\left(J_{3,26}=8.8 \mathrm{~Hz}\right)$ and by the fact that there is no NOE correlation could be detected among them in the NOESY spectrum. The NOE correlations from the proton of $26-\mathrm{OH}$ to the protons of $12-\mathrm{OH}$ and $13-\mathrm{OH}$ implied the same direction of these $\mathrm{OH}$ groups, while the observed NOE correlation from H-3 to the olefinic H-22 indicated the same orientation of H-3 and CH-22 (Figure 2). Unfortunately, the NOESY data for compound 2 proved to be insufficient to solve the relative configuration at C-6. However, based on the fact of the very similar NMR data of H-6 to H-9 and of C-6 to C-9 (Table 1) in $\mathbf{1}$ and 2, as well as from the biogenetic consideration, the configuration of H- 6 was assigned as $\alpha$-orientation, the same as that of compound $\mathbf{1}$.

The absolute configuration of $\mathbf{2}$ was also determined by amino acid analysis of its acidic hydrolysate (Figure 5), which assigned $S$-configuration for C-6. The other chiral centers in 2 were therefore deduced as $3 R, 12 R, 13 S, 21 R$, and $26 S$. The structure for compound $\mathbf{2}$ was thus determined and it was named as 26-hydroxyverruculogen.

Compound 3 was also isolated as a pale amorphous solid. Its molecular formula was determined to be $\mathrm{C}_{32} \mathrm{H}_{41} \mathrm{~N}_{3} \mathrm{O}_{8}$ on the basis of HRESIMS data. Detailed comparison of the 1D and 2D NMR data of 3 with those of 2 revealed the same structural features, except for the presence of five additional carbon signals at $\delta_{\mathrm{C}} 68.5\left(\mathrm{CH}_{2}, \mathrm{C}-30\right), 122.2(\mathrm{CH}, \mathrm{C}-31), 134.5(\mathrm{C}, \mathrm{C}-32), 18.1\left(\mathrm{CH}_{3}, \mathrm{C}-33\right)$, and 25.2 $\left(\mathrm{CH}_{3}, \mathrm{C}-34\right)$ in the ${ }^{13} \mathrm{C}$ NMR spectrum of $\mathbf{3}$, which ascribable to the presence of a prenyl moiety in 3. The ${ }^{1} \mathrm{H}$ NMR spectrum displayed the corresponding signals for the prenyl motif at $\delta_{\mathrm{H}} 4.56 / 4.88$ $\left(\mathrm{H}_{2}-30\right), 5.57(\mathrm{H}-31), 1.75\left(\mathrm{H}_{3}-33\right)$, and $1.77\left(\mathrm{H}_{3}-34\right)$. The attachment of the prenyl unit at $\mathrm{C}-13$ was evidenced by the observed HMBC correlation from H-13 to the oxygenated carbon C-30 (Figure 2).

The relative configuration of compound $\mathbf{3}$ was determined by proton coupling constant and NOESY spectrum. The large coupling constant $(9.0 \mathrm{~Hz})$ of H-3 and H-26 (Table 1) indicated that the two protons located on the different face of the molecule. The observed NOE correlations from 12-OH to 26-OH and H-9 $\alpha$ and from $\mathrm{H}-9 \alpha$ to H-6 suggested the same orientation of these groups (Figure 3), while the correlations from $\mathrm{H}-3$ to $\mathrm{H}-22$ and from $\mathrm{H}-26$ to $\mathrm{H}-13$ indicated that $\mathrm{H}-3, \mathrm{H}-22$, and 13-O-isoprenyl units located on the same face with $26-\mathrm{OH}$. The absolute configuration of C-6 was also determined as $S$ by chiral HPLC analysis of the hydralates and the absolute configuration of compound 3 was thus established as $3 R, 6 S, 12 R, 13 S, 21 R$, and $26 S$, same as that of $\mathbf{2}$. Compound $\mathbf{3}$ was named as 13-O-prenyl-26-hydroxyverruculogen.

In addition to the new compounds 1-3, four known homologues verruculogen (4) [4,5], fumitremorgin A (5) [2], cyclotryprostatin A (6) [3], and TR-2 (7) [4], were also isolated and identified from the culture extracts of $P$. brefeldianum SD-273.

\subsection{Biological Activities of the Isolated Compounds}

The isolated compounds 1-7 were examined for antibacterial, cytotoxicity, and brine shrimp lethality. None of them showed potent antibacterial activity against two bacteria (Escherichia coli and Staphyloccocus aureus), or cytotoxicity against eight tumor cell lines (B16, HuH-7, SW-1990, Hela, 
Du145, H460, MCF-7, and SGC-7901). However, compound 3 showed potent lethality against brine shrimp (Artemia salina), with $\mathrm{LD}_{50}$ value of $9.44 \mu \mathrm{M}$, while the positive control colchicine had the $\mathrm{LD}_{50}$ value of $99.0 \mu \mathrm{M}$, and the activity might be related to the prenyl substitution at $13-\mathrm{OH}$.

\section{Experimental Section}

\subsection{General}

The melting point was determined with an SGW X-4 micro-melting-point apparatus. The optical rotations were measured on an Optical Activity A-55 polarimeter. UV data were obtained on a Lengguang Gold S54 spectrophotometer. The ${ }^{1} \mathrm{H},{ }^{13} \mathrm{C}$, and 2D NMR spectroscopic data were recorded on Bruker Advance 500 spectrometer. Mass spectra were measured on a VG Autospec 3000 mass spectrometer. HPLC analysis was performed using a Dionex HPLC System equipped with a P680 pump, an ASI-100 automated sample injector, a TCC-100 column oven, a UV-DAD 340U detector, and a Dionex Acclaim ODS column $(4.6 \times 250 \mathrm{~mm}, 5 \mu \mathrm{m})$. Semi-preparative HPLC was operated using a Dionex UltiMate U3000 system using an Agilent Prep RP-18 column $(21.2 \times 250 \mathrm{~mm}, 10 \mu \mathrm{m})$ with UV detection. A Phenomenex-Chirex 3126 N,S-dioctyl-(D)-penicillamine column $(250 \times 4.60 \mathrm{~mm}$, $5 \mu \mathrm{m}$ ) was used for chiral HPLC analysis. Column chromatography (CC) was performed with silica gel (200-300 mesh, Qingdao Marine Chemical Factory, Qingdao, Shandong, China), Lobar LiChroprep RP-18 (40-63 $\mu \mathrm{m}$; Merck, Darmstadt, Germany), and Sephadex LH-20 (18-110 $\mu \mathrm{m}$, Merck, Darmstadt, Germany).

\subsection{Fungal Material}

The fungus Penicillium brefeldianum SD-273 was isolated from a sediment sample collected from the estuary of the Pearl River in South China Sea at a depth of $100 \mathrm{~m}$, in October 2010. The fungal strain grew fast on potato dextrose agar plate and the pale yellow mycelia with few spores could be observed in about 3 days at $28^{\circ} \mathrm{C}$. Fungal identification was carried out using a molecular biological protocol by DNA amplification and sequencing of the ITS region as well as by calmodulin (cmd) sequencing as described previously [16]. The sequence data derived from the fungal strain have been submitted to and deposited at GenBank under accession no. JQ306332 (ITS) and KJ160447 (cmd). A BLAST search result showed that the ITS rDNA sequence was same (100\%) to the sequence of Eupenicillium brefeldianum B37 (GenBank accession no. EF488446. It should be noted that the genus Eupenicilium is not used anymore and was re-defined to belong in Penicillium [17]), while the calmodulin sequence of the strain SD-273 was similar (99\%) to that of Eupenicillium brefeldianum AS3.6689 (accession no. AY678593). The strain is preserved at China General Microbiological Culture Collection Center, CGMCC (Culture Collection Number CGMCC 7.160).

\subsection{Fermentation}

For chemical investigation, the fungal strain was statically cultivated in liquid potato-dextrose broth medium (1000 $\mathrm{mL}$ seawater, $20 \mathrm{~g}$ glucose, $5 \mathrm{~g}$ peptone, $3 \mathrm{~g}$ yeast extract, $\mathrm{pH}$ 6.5-7.0, liquid medium/flask $=300 \mathrm{~mL}$ ) in $1 \mathrm{~L}$ Erlenmeyer flasks for 30 days at room temperature. 


\subsection{Extraction and Isolation}

The fermented whole broth $(300 \mathrm{~mL} \times 100$ flasks $)$ was filtered through cheesecloth to separate the culture broth and mycelia, which were extracted with EtOAc and $\mathrm{MeOH}$, respectively. The two extracts were combined for further separation since their HPLC and TLC profiles were almost identical. The combined extracts $(45.1 \mathrm{~g})$ were subjected to Si gel vacuum liquid chromatography (VLC) using $\mathrm{CHCl}_{3}-\mathrm{MeOH}$ gradient elution to get eight fractions (Frs.1-8). Fr.7 (5.0 g) was subjected to column chromatography (CC) on silica gel eluted with petroleum ether-EtOAc (from 20:1 to 1:1) to give eight subfractions (Frs.7.1-7.8). Fr.7.6 (67.0 mg) was further purified by CC on Sephadex LH-20 $(\mathrm{MeOH})$ and preparative TLC to obtain compound 5 (17.9 $\mathrm{mg})$. Fr.8 (6.3 g) was further separated by $\mathrm{CC}$ on reversed phase silica gel $\mathrm{C} 18$ with a $\mathrm{MeOH}-\mathrm{H}_{2} \mathrm{O}$ gradient (from $20 \%$ to $100 \%$ ) to get nine subfractions (Frs.8.1-8.9). Fr.8.5 (410.0 $\mathrm{mg}$ ) was subjected to semi-preparative HPLC (Dionex UltiMate U3000, $21.2 \times 250 \mathrm{~mm}, 10 \mu \mathrm{m}, 85 \%$ aqueous $\mathrm{MeOH}, 16 \mathrm{~mL} / \mathrm{min}$ ) to afford compounds 6 $\left(99.0 \mathrm{mg}, t_{\mathrm{R}} 10.2 \mathrm{~min}\right)$ and $4\left(44.0 \mathrm{mg}, t_{\mathrm{R}} 12.1 \mathrm{~min}\right)$. Fr.8.7 (230.0 mg) was purified by preparative TLC $\left(\mathrm{CHCl}_{3}-\mathrm{MeOH}, 15: 1\right)$ to yield compounds 1 (16.0 mg) and 2 (14.0 mg). Fr.8.9 (224.0 mg) was further subjected to CC on Sephadex LH-20 to obtain compounds 3 (8.6 mg) and 7 (5.4 mg).

24-Hydroxyverruculogen (1): colorless crystals $\left(\mathrm{CH}_{3} \mathrm{Cl}-\mathrm{MeOH}, 1: 1\right) ; \mathrm{mp} 246-248{ }^{\circ} \mathrm{C} ;[\alpha]_{\mathrm{D}}^{20}-12.5$ (c 0.24, MeOH); UV (MeOH) $\lambda_{\max }(\log \varepsilon) 223$ (4.51), 268 (3.70), 288 (3.64) nm; ${ }^{1} \mathrm{H}$ and ${ }^{13} \mathrm{C} \mathrm{NMR}$ data, see Table 1; ESIMS $m / z 550[\mathrm{M}+\mathrm{Na}]^{+}$; HRESIMS $m / z 550.2153[\mathrm{M}+\mathrm{Na}]^{+}$(calcd for $\left.\mathrm{C}_{27} \mathrm{H}_{33} \mathrm{~N}_{3} \mathrm{O}_{8} \mathrm{Na}^{+}, 550.2165, \Delta-1.2 \mathrm{mmu}\right)$.

26-Hydroxyverruculogen (2): pale amorphous solid $(\mathrm{MeOH}) ;[\alpha]_{\mathrm{D}}^{20}-75.5$ (c $\left.0.23, \mathrm{MeOH}\right)$; UV (MeOH) $\lambda_{\max }(\log \varepsilon) 223$ (4.45), 271 (3.59), 287 (3.54) nm; ${ }^{1} \mathrm{H}$ and ${ }^{13} \mathrm{C}$ NMR data, see Table 1; ESIMS $m / z 550[\mathrm{M}+\mathrm{Na}]^{+}$; HRESIMS $m / z 550.2156[\mathrm{M}+\mathrm{Na}]^{+}$(calcd for $\mathrm{C}_{27} \mathrm{H}_{33} \mathrm{~N}_{3} \mathrm{O}_{8} \mathrm{Na}^{+}, 550.2165$, $\Delta-0.9 \mathrm{mmu})$.

13-O-Prenyl-26-hydroxyverruculogen (3): pale amorphous solid $(\mathrm{MeOH}) ;[\alpha]_{\mathrm{D}}^{20}-10.1(c \mathrm{c}$ 0.35, $\mathrm{MeOH})$; UV (MeOH) $\lambda_{\max }(\log \varepsilon) 227$ (4.60), 275 (3.88), 289 (3.80) nm; ${ }^{1} \mathrm{H}$ and ${ }^{13} \mathrm{C}$ NMR data, see Table 1; ESIMS $m / z 618[\mathrm{M}+\mathrm{Na}]^{+}$; HRESIMS $m / z 618.2804[\mathrm{M}+\mathrm{Na}]^{+}$(calcd for $\mathrm{C}_{32} \mathrm{H}_{41} \mathrm{~N}_{3} \mathrm{O}_{8} \mathrm{Na}^{+}, 618.2791$, $\Delta+1.3 \mathrm{mmu})$.

\subsection{X-ray Crystallographic Analysis of Compound $\mathbf{1}$}

All crystallographic data [18] were collected on a Bruker Smart-1000 CCD diffractometer equipped with graphite-monochromatic Mo K $\alpha$ radiation $(\lambda=0.71073 \AA)$ at 293(2) K. The data were corrected for absorption by using the program SADABS [19]. The structure was solved by direct methods with the SHELXTL software package [20]. All non-hydrogen atoms were refined anisotropically. The $\mathrm{H}$ atoms were located by geometrical calculations, and their positions and thermal parameters were fixed during the structure refinement. The structure was refined by full-matrix least-squares techniques [21].

Crystal data for 1: $\mathrm{C}_{27} \mathrm{H}_{33} \mathrm{~N}_{3} \mathrm{O}_{8}$; F.W. = 527.56; orthorhombic space group P2(1)2(1)2(1); unit cell dimensions $a=11.0113(9) \AA, b=13.2224(8) \AA, c=17.6195(7) \AA, V=2565.3(3) \AA^{3}, \alpha=\beta=\gamma=90^{\circ}$, $Z=4, d_{\text {calcd }}=1.366 \mathrm{mg} / \mathrm{m}^{3}$, crystal dimensions $0.35 \times 0.18 \times 0.12 \mathrm{~mm}, \mu=0.101 \mathrm{~mm}^{-1}, F(000)=1120$. The 6266 measurements yielded 4426 independent reflections after equivalent data were averaged, and 
Lorentz and polarization corrections were applied. The final refinement gave $R_{1}=0.0604$ and $\mathrm{w} R_{2}=0.0972[I>2 \sigma(I)]$.

\subsection{Amino Acid Analysis}

Compounds $1(1.0 \mathrm{mg}), 2(0.9 \mathrm{mg})$, and $\mathbf{3}(0.8 \mathrm{mg})$ were each dissolved in $10 \mathrm{~mL} 6 \mathrm{~N} \mathrm{HCl}$ and heated at $110{ }^{\circ} \mathrm{C}$ for $24 \mathrm{~h}$ in sealed tubes. The solutions were then evaporated to dryness under reduced pressure. Each sample, including the standard amino acids L-pro and D-pro, was dissolved in $1 \mathrm{~mL}$ of eluting solvent ( $2 \mathrm{mM} \mathrm{CuSO}_{4} \cdot 5 \mathrm{H}_{2} \mathrm{O}$, with $5 \mathrm{~mL} \mathrm{CH} \mathrm{CH}_{3} \mathrm{CN}$ in every $100 \mathrm{~mL}$ solvent $)$ and was centrifuged at a speed of 12,000 rpm to get corresponding supernate for chiral HPLC analysis, which was carried out using a Phenomenex-Chirex-3126 column at $254 \mathrm{~nm}$ with flow rate $1.0 \mathrm{~mL} / \mathrm{min}$ at $40{ }^{\circ} \mathrm{C}$. The HPLC analysis showed that the products of acidic hydrolysis of 1-3 contained the identical amino acids, which have the same retention time as that of the standard L-pro. The results established the chiral center of the proline moiety in the structure of the three compounds to be $S$-configuration (Figure 5).

\subsection{Brine Shrimp Toxicity}

Brine shrimp (Artemia salina) toxicity of the isolated compounds was determined as described previously [22]. Colchicine was used as a positive control.

\subsection{Cytotoxicity Assay}

The cytotoxic activity against B16 (murine melanoma), HuH-7 (hepatocarcinoma), SW-1990 (human pancreatic adenocarcinoma), Hela (human epithelial carcinoma), Du145 (human prostate carcinoma), H460 (non-small cell lung cancer), MCF-7 (human breast adenocarcinoma), and SGC-7901 (human gastric cancer) cell lines were determined according to previously reported methods [23].

\subsection{Antibacterial Assay}

Antibacterial assay against E. coli and $S$. aureus was carried out using the well diffusion method [24]. Chloromycetin was used as a positive control.

\section{Conclusions}

In summary, three new indolediketopiperazine derivatives (1-3) as well as four known related homologues (4-7) were isolated and identified from the culture extract of the marine sediment-derived fungus $P$. brefeldianum SD-273 and the structures and absolute configuration were determined based on the extensive interpretation of spectroscopic data, X-ray crystallographic diffraction, and chiral HPLC analysis. Although none of these compounds showed potent antibacterial activity or cytotoxicity, compound $\mathbf{3}$ showed potent lethal activity against brine shrimp.

\section{Acknowledgments}

Financial support from the Ministry of Science and Technology of China (2013AA092901 and 2012AA092104) and from the Natural Science Foundation of China (31270403) is gratefully 
acknowledged. The authors appreciate Y.-S. Wang at the South China Sea Institute of Oceanology of the Chinese Academy of Sciences for his help in sediment sampling.

\section{Conflicts of Interest}

The authors declare no conflict of interest.

\section{References}

1. Wang, W.L.; Lu, Z.Y.; Tao, H.W.; Zhu, T.J.; Fang, Y.C.; Gu, Q.Q.; Zhu, W.M. Isoechinulin-type alkaloids, variecolorins A-L, from halotolerant Aspergillus variecolor. J. Nat. Prod. 2007, 70, 1558-1564.

2. Yamazaki, M.; Fujimoto, H.; Kawasaki, T. Chemistry of tremorogenic metabolites. I. Fumitremorgin A from Aspergillus fumigatus. Chem. Pharm. Bull. 1980, 28, 245-254.

3. Cui, C.B.; Kakeya, H.; Osada, H. Novel mammalian cell cycle inhibitors, tryprostatins A, B and other diketopiperazines produced by Aspergillus fumigatus II. Physico-chemical properties and structures. J. Antibiot. 1996, 49, 534-540.

4. Cole, R.J.; Kirksey, J.W.; Cox, R.H.; Clardy, J. Structure of the tremor-producing indole, TR-2. J. Agric. Food Chem. 1975, 23, 1015-1018.

5. Fayos, J.; Lokensgard, D.; Clardy, J.; Cole, R.J.; Kirksey, J.W. Structure of verruculogen, a tremor producing peroxide from Penicillium verruculosum. J. Am. Chem. Soc. 1974, 21, 6785-6787.

6. Du, F.Y.; Li, X.M.; Li, C.S.; Shang, Z.; Wang, B.G. Cristatumins A-D, new indole alkaloids from the marine-derived endophytic fungus Eurotium cristatum EN-220. Bioorg. Med. Chem. Lett. 2012, 22, 4650-4653.

7. Wang, F.; Fang, Y.; Zhu, T.; Zhang, M.; Lin, A.; Gu, Q.; Zhu, W. Seven new prenylated indole diketopiperazine alkaloids from holothurian-derived fungus Aspergillus fumigatus. Tetrahedron 2008, 64, 7986-7991.

8. Willingale, J.; Perera, K.P.W.C.; Mantle, P.G. An intermediary role for the tremorgenic mycotoxin TR-2 in the biosynthesis of verruculogen. Biochem. J. 1983, 214, 991-993.

9. An, C.Y.; Li, X.M.; Li, C.S.; Wang, M.H.; Xu, G.M.; Wang, B.G. Aniquinazolines A-D, four new quinazolinone alkaloids from marine-derived endophytic fungus Aspergillus nidulans. Mar. Drugs 2013, 11, 2682-2694.

10. Wang, M.H.; Li, X.M.; Li, C.S.; Ji, N.Y.; Wang, B.G. Secondary metabolites from Penicillium pinophilum SD-272, a marine sediment-derived fungus. Mar. Drugs 2013, 11, 2230-2238.

11. Li, C.S.; Li, X.M.; Gao, S.S.; Lu, Y.H.; Wang, B.G. Cytotoxic anthranilic acid derivatives from deep sea sediment-derived fungus Penicillium paneum SD-44. Mar. Drugs 2013, 11, 3068-3076.

12. Zhao, Y.; Chen, H.; Shang, Z.; Jiao, B.; Yuan, B.; Sun, W.; Wang, B.; Miao, M.; Huang, C. SD118-xanthocillin X (1), a novel marine agent extracted from Penicillium commune, induces autophagy through the inhibition of the MEK/ERK pathway. Mar. Drugs 2012, 10, 1345-1359.

13. An, C.Y.; Li, X.M.; Li, C.S.; Gao, S.S.; Shang, Z.; Wang, B.G. Triazoles and other $N$-containing metabolites from the marine-derived endophytic fungus Penicillium chrysogenum EN-118. Helv. Chim. Acta 2013, 96, 682-687. 
14. Zhang, Y.; Li, X.M.; Shang, Z.; Li, C.S.; Ji, N.Y.; Wang, B.G. Cytoglobosins A-G, cytochalasans from a marine-derived endophytic fungus, Chaetomium globosum QEN-14. J. Nat. Prod. 2010, $73,729-733$.

15. Sun, H.F.; Li, X.M.; Meng, L.; Cui, C.M.; Gao, S.S.; Li, C.S.; Huang, C.G.; Wang, B.G. Asperolides A-C, tetranorlabdane diterpenoids from the marine alga-derived endophytic fungus Aspergillus wentii EN-48. J. Nat. Prod. 2012, 75, 148-152.

16. Wang, S.; Li, X.M.; Teuscher, F.; Li, D.L.; Diesel, A.; Ebel, R.; Proksch, P.; Wang, B.G. Chaetopyranin, a benzaldehyde derivative, and other related metabolites from Chaetomium globosum, an endophytic fungus derived from the marine red alga Polysiphonia urceolata. J. Nat. Prod. 2006, $69,1622-1625$.

17. Houbraken, J.; Samson, R.A. Phylogeny of Penicillium and the segregation of Trichocomaceae into three families. Stud. Mycol. 2011, 70, 1-51.

18. Cambridge Crystallographic Data Centre (CCDC). Deposition No. CCDC923360. Available online: http://www.ccdc.cam.ac.uk/data_request/cif (accessed on 6 February 2013).

19. Sheldrick, G.M. SADABS, Software for Empirical Absorption Correction; University of Göttingen: Göttingen, Germany, 1996.

20. Sheldrick, G.M. SHELXTL, Structure Determination Software Programs; Bruker Analytical X-ray System Inc.: Madison, WI, USA, 1997.

21. Sheldrick, G.M. SHELXL-97 and SHELXS-97, Program for X-ray Crystal Structure Solution and Refinement; University of Göttingen: Göttingen, Germany, 1997.

22. Meyer, B.N.; Ferrigni, N.R.; Putnam, J.E.; Jacobsen, L.B.; Nichols, D.E.; McLaughlin, J.L. Brine shrimp: A convenient general bioassay for active plant constituents. Planta Med. 1982, 45, 31-34.

23. Bergeron, R.J.; Cavanaugh, P.F., Jr.; Kline, S.J.; Hughes, R.G., Jr.; Elliott, G.T.; Porter, C.W. Antineoplastic and antiherpetic activity of spermidine catecholamide iron chelators. Biochem. Biophys. Res. Commun. 1984, 121, 848-854.

24. Al-Burtamani, S.K.S.; Fatope, M.O.; Marwah, R.G.; Onifade, A.K.; Al-Saidi, S.H. Chemical composition, antibacterial and antifungal activities of the essential oil of Haplophyllum tuberculatum from Oman. J. Ethnopharmacol. 2005, 96, 107-112.

(C) 2014 by the authors; licensee MDPI, Basel, Switzerland. This article is an open access article distributed under the terms and conditions of the Creative Commons Attribution license (http://creativecommons.org/licenses/by/3.0/). 